\title{
A Clinical Experience with Decompressive Craniectomy
}

\author{
Ozgur DEMIR, Fatih Ersay DENIZ \\ Gaziosmanpasa University, School of Medicine, Department of Neurosurgery, Tokat, Turkey \\ Corresponding author: Ozgur DEMIR cerendemir40@gmail.com
}

\section{ABSTRACT}

AIM: To investigate the patients who underwent decompressive craniectomy (DC) for trauma or cerebrovascular disease, and to determine the most suitable treatment protocol for those patients.

MATERIAL and METHODS: Overall, 32 patients with trauma or cerebrovascular disease underwent DC. Clinical, radiological and surgical data of surviving patients was retrospectively analysed. The occurence of favourable and unfavourable outcomes during the course of their treatment were recorded.

RESULTS: We detected ventriculomegaly in nine out of the 32 patients (9/32, 28.1\%) after DC. Of these nine, four patients (4/9, $44.4 \%$ ) underwent shunt surgery. Cranioplasty performed in 29 of the 32 patients caused epidural hygroma in 13 of them (13/29, $44.8 \%)$. Of these 13 patients, three underwent surgery because of progressive increase in the size of hygromas. In the remaining patients, the epidural hygromas regressed spontaneously. Glasgow coma score (GCS) before and after DC surgery ( $p=0.011$ and $p=0.006$, respectively), timing of cranioplasty $(p=0.028)$, midline shift $(p=0.048)$ and craniectomy size $(p=0.047)$ were significantly associated with ventriculomegaly.

CONCLUSION: Lower GCS, delayed cranioplasty, greater midline shift and larger craniectomy size were found to be associated with hydrocephalus after DC. To avoid hydrocephalus, it may be beneficial to perform shunt surgery first followed by cranioplasty in a single surgical procedure. Additionally, epidural hygromas frequently encountered after a cranioplasty that should be considered and followed up carefully.

KEYWORDS: Decompressive craniectomy, Cerebrovascular disease, Trauma

\section{INTRODUCTION}

$\mathrm{D}$ ecompressive craniectomy (DC) is a well-known surgical procedure that involves removal of a part of the cranium in order to relieve high intracranial pressure (ICP). Several studies have demonstrated the benefit of DC in reducing ICP $(11,22)$. DC has been used in cases of traumatic brain injury, malignant middle cerebral artery infarction and subarachnoid haemorrhage $(3,6,24)$. However, no standardised procedure for performing DC is defined in the literature. Therefore, a variety of methods including different shapes and sizes of DC are often used. Ideally, the size of the craniectomy should be based on the pathology for appropriate decompression. Although craniectomy without durotomy has been shown to lower ICP, craniectomy with durotomy can lower ICP better than craniectomy alone $(2,13)$. Furthermore, several DC-mediated complications including hydrocephalus, epidural hygroma, sinking flap syndrome and subdural hematoma have been reported in the literature $(5$, 23). The aim of this study is to provide recommendations for managing patients following DC based on data from our clinic.

\section{MATERIAL and METHODS}

This study retrospectively enrolled 32 patients who had undergone DC surgery between 2011 and 2016. The study was approved by the Gaziosmanpasa University clinical investigation ethics committee (19-KAEK-022). Patients were aged between 5 and 78 years, with a mean age of 41.2 years. Demographically, the patient population comprised of seven (21.9\%) females and $25(78.1 \%)$ males. The duration between admission and DC surgery ranged from 1 to 4 days with a mean interval of 1.8 days. DC was performed in 12 patients with cerebrovascular disease and in 20 trauma patients. 
Cerebrovascular disease included malignant middle cerebral artery infarct and intracerebral hematoma. Trauma included subdural hematoma, traumatic subarachnoid haemorrhage, contusion and cerebral oedema. The mean follow-up period for patients was 8.6 months. The mean interval between DC and cranioplasty was 8.2 months. All DC surgeries were performed via a standard unilateral frontoparietotemporal craniectomy with durotomy. Patients with traumatic brain injury and cerebrovascular disease were included in the study. Patients who died in the early period of follow-up were excluded.

The clinical and radiological data for each patient in the initial and follow-up assessments was retrospectively analysed. The pathology type, Glasgow coma score (GCS), timing of cranioplasty, midline shift, area of craniectomy, presence of hydrocephalus, presence of epidural hygroma and surgical data were recorded for each patient.

Patients with persistent ventricular dilatation without associated clinical deterioration were considered to be ventriculomegalic patients. Patients with progressive ventricular dilatation and associated deterioration were considered to be hydrocephalic.

Recorded data were statistically analysed. Mann-Whitney U-test, Fisher's exact test and independent samples t-test were used for statistical analysis. p-value of less than 0.05 was considered statistically significant.

\section{RESULTS}

The GCS values before and after DC ranged from 4 to 15 (mean 7.3) and 6 to 15 (mean 12.7), respectively. The midline shift prior to DC ranged from 0 to $20 \mathrm{~mm}$ (mean $6.8 \mathrm{~mm}$ ). The craniectomy area ranged from $25 \mathrm{~cm}^{2}$ to $133.6 \mathrm{~cm}^{2}$ (mean $61.7 \mathrm{~cm}^{2}$ ). Ventriculomegaly after DC surgeries was observed in nine $(9 / 32,28.1 \%)$ patients. Shunt-dependent hydrocephalus was observed in four of the nine patients with ventriculomegaly. Consequently, the incidence of shuntdependent hydrocephalus was $12.5 \%$ (4/32) of the total study population. Shunt surgery was initially performed in two patients with newly developed hydrocephalus. This caused midline shift and over-drainage of cerebrospinal fluid (CSF) at atmospheric pressure (Figure 1A-E). Therefore, in the next two patients, shunt surgery and cranioplasty procedures were both performed in a single surgery. In all, 29 out of the 32 $(90.6 \%)$ patients with DC underwent cranioplasty. Autogenous graft was used in 23 patients and heterogenous graft was used in six patients. Epidural hygroma was detected in 13 patients with cranioplasty $(13 / 29,44.8 \%)$. Two $(2 / 6,33.3 \%)$ of them had cranioplasty with heterogenous graft and 11 (11/23, $47.8 \%)$ had cranioplasty with autogenous graft. Hygroma spontaneously regressed in $10(10 / 13,76.9 \%)$ patients (Table I) but progressed in three of them $(3 / 13,23.1 \%)$. These three patients were re-operated upon to evacuate the hygroma via epidural drain replacement (Figure 2A, B).

Statistical analysis revealed significant correlation between midline shift and ventriculomegaly $(p=0.048)$. Greater midline shift was associated with increased risk of hydrocephalus.

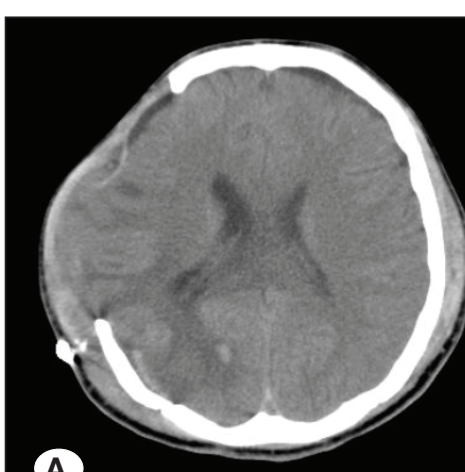

(A)

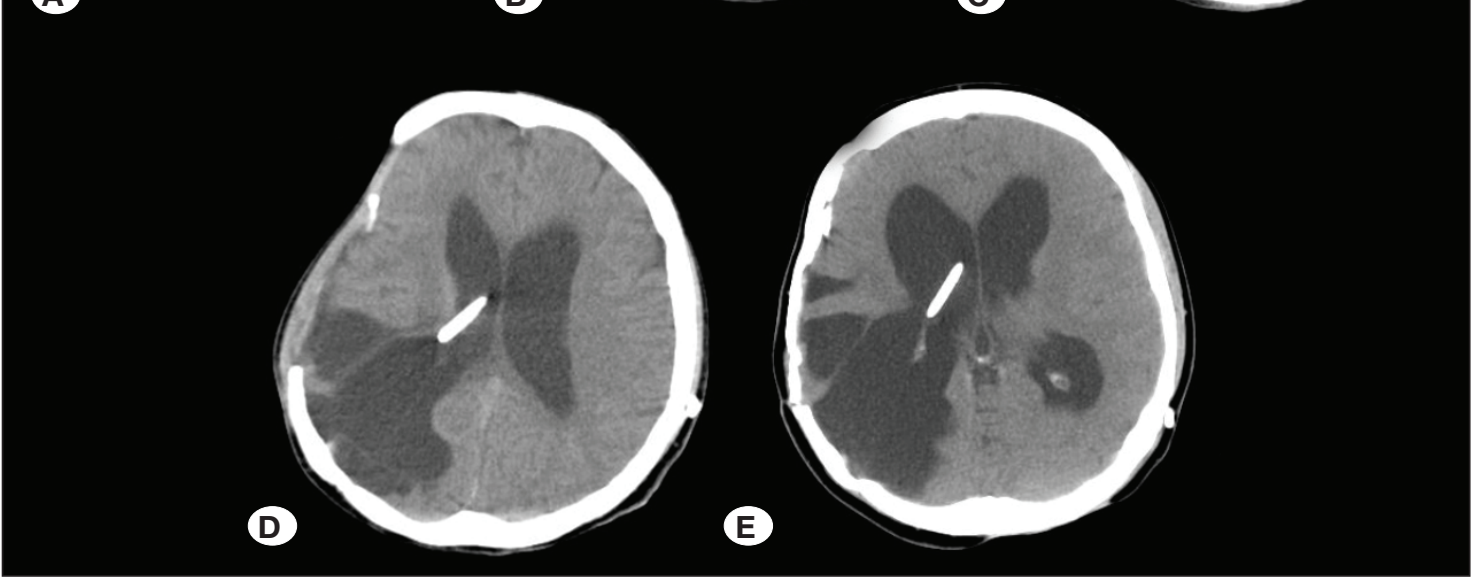

Figure 1: Computed tomography $(\mathrm{CT})$ scans showing DC surgery after trauma (A), hydrocephalus development following DC (B), midline shift and CSF over-drainage at atmospheric pressure after shunt surgery (C). CT showing that midline shift has vanished after shunt system is closed (D), and CT showing the view after cranioplasty surgery and shunt opening (E). 
Craniectomy area and ventriculomegaly were also significantly correlated $(p=0.047)$. An increase in the craniectomy area was associated with increased incidence of hydrocephalus. GCS values before and after DC surgery correlated significantly

Table I: Baseline Characteristics of Variables

\begin{tabular}{|c|c|c|c|}
\hline \multirow{2}{*}{ Variables } & & \multicolumn{2}{|c|}{ Value } \\
\hline & & $\mathbf{n}$ & $\%$ \\
\hline \multirow{2}{*}{ Gender } & Female & 7 & 21.9 \\
\hline & Male & 25 & 78.1 \\
\hline \multirow{2}{*}{ Ventriculomegaly } & Absent & 23 & 71.9 \\
\hline & Present & 9 & 28.1 \\
\hline \multirow{2}{*}{ Shunt surgery } & Absent & 28 & 87.5 \\
\hline & Present & 4 & 12.5 \\
\hline \multirow{2}{*}{ Epidural hygroma } & Absent & 19 & 59.4 \\
\hline & Present & 13 & 40.6 \\
\hline \multirow{2}{*}{$\begin{array}{l}\text { Cranioplasty heterogenous } \\
\text { graft }\end{array}$} & Absent & 26 & 81.3 \\
\hline & Present & 6 & 18.7 \\
\hline \multirow{3}{*}{$\begin{array}{l}\text { Cranioplasty autogenous } \\
\text { graft }\end{array}$} & Absent & 9 & 28.1 \\
\hline & Present & 23 & 71.9 \\
\hline & & \multicolumn{2}{|c|}{ Mean \pm SD } \\
\hline Age (years) & & \multicolumn{2}{|c|}{$41.22 \pm 19.71$} \\
\hline Midline shift (mm) & & \multicolumn{2}{|c|}{$6.81 \pm 4.64$} \\
\hline Craniectomy area $\left(\mathrm{cm}^{2}\right)$ & & \multicolumn{2}{|c|}{$61.66 \pm 23.05$} \\
\hline GCS before DC & & \multicolumn{2}{|c|}{$7.34 \pm 3.2$} \\
\hline GCS after DC & & \multicolumn{2}{|c|}{$12.69 \pm 3.29$} \\
\hline
\end{tabular}

Data are shown as Mean \pm SD or n(\%).

DC: Decompressive craniectomy, GCS: Glasgow Coma Scale, SD: Standard deviation. with ventriculomegaly ( $p=0.011$ and $p=0.006$, respectively). Lower GCS value before and after DC were associated with hydrocephalus. Pre-operative GCS differed significantly from post-operative GCS $(p<0.001)$. Post-operative GCS in the group with ventriculomegaly was significantly higher than the group without ventriculomegaly $(p<0.001)$ (Table II, Figure 3$)$.

Statistically significant association was also found between hydrocephalus and pre-operative GCS ( $p=0.036)$, post-operative GCS $(p=0.036)$ and midline shift $(p=0.039)$, but not between hydrocephalus and craniectomy area $(p=0.177)$. There was also significant difference between pre-operative GCS and post-operative GCS ( $p=0.003$ ). Post-operative GCS was significantly lower in the group with hydrocephaly compared to the group without hydrocephaly $(\mathrm{p}<0.001)$ (Table III).

There was significant association between ventriculomegaly and delayed cranioplasty $(p=0.028)$. In this study, ventriculomegaly was more common in patients who underwent delayed cranioplasty (Table IV).

Table II: Distribution of Quantitative Variables in Patients with Ventriculomegaly

\begin{tabular}{lccc}
\hline & \multicolumn{2}{c}{ Ventriculomegaly } & \\
\cline { 2 - 3 } & $\begin{array}{c}\text { Absent } \\
(\mathbf{n}=\mathbf{2 3})\end{array}$ & $\begin{array}{c}\text { Present } \\
(\mathbf{n}=\mathbf{9})\end{array}$ & $\mathbf{p}_{\mathbf{1}}$ \\
\hline Age & $42.48 \pm 20.32$ & $38 \pm 18.79$ & 0.572 \\
\hline Midline shift & $5.80 \pm 3.89$ & $9.39 \pm 5.61$ & $\mathbf{0 . 0 4 8}$ \\
\hline Craniectomy area & $56.64 \pm 18.26$ & $74.49 \pm 29.75$ & $\mathbf{0 . 0 4 7}$ \\
\hline GCS before DC & $8.22 \pm 3.07$ & $5.11 \pm 2.42$ & $\mathbf{0 . 0 1 1}$ \\
\hline GCS after DC & $13.65 \pm 1.87$ & $10.22 \pm 4.76$ & $\mathbf{0 . 0 0 6}$ \\
\hline $\mathrm{p}_{2}$ & $<\mathbf{0 . 0 0 1}$ & $<\mathbf{0 . 0 0 1}$ & \\
\hline
\end{tabular}

$\boldsymbol{p}_{1}$ : Comparison between groups, $\boldsymbol{p}_{2}$ : comparison within a group. Variance analysis was used in repeated measures. DC: Decompressive craniectomy, GCS: Glasgow Coma Scale.
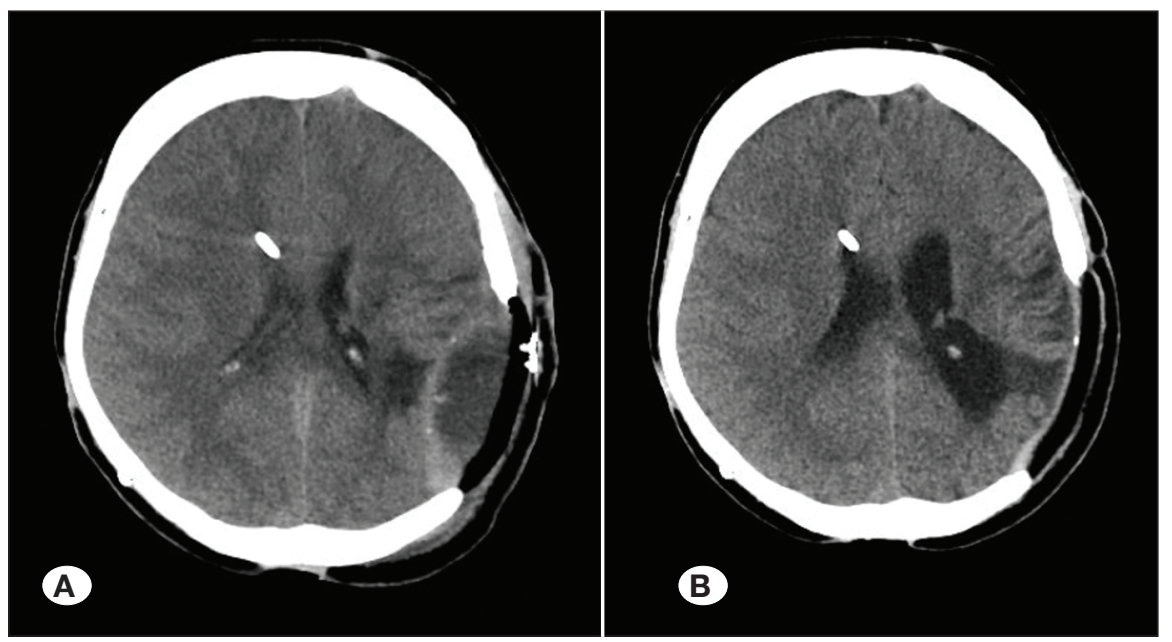

Figure 2: CT scan showing the development of epidural hygroma (A), and view after evacuation of the hygroma (B). 


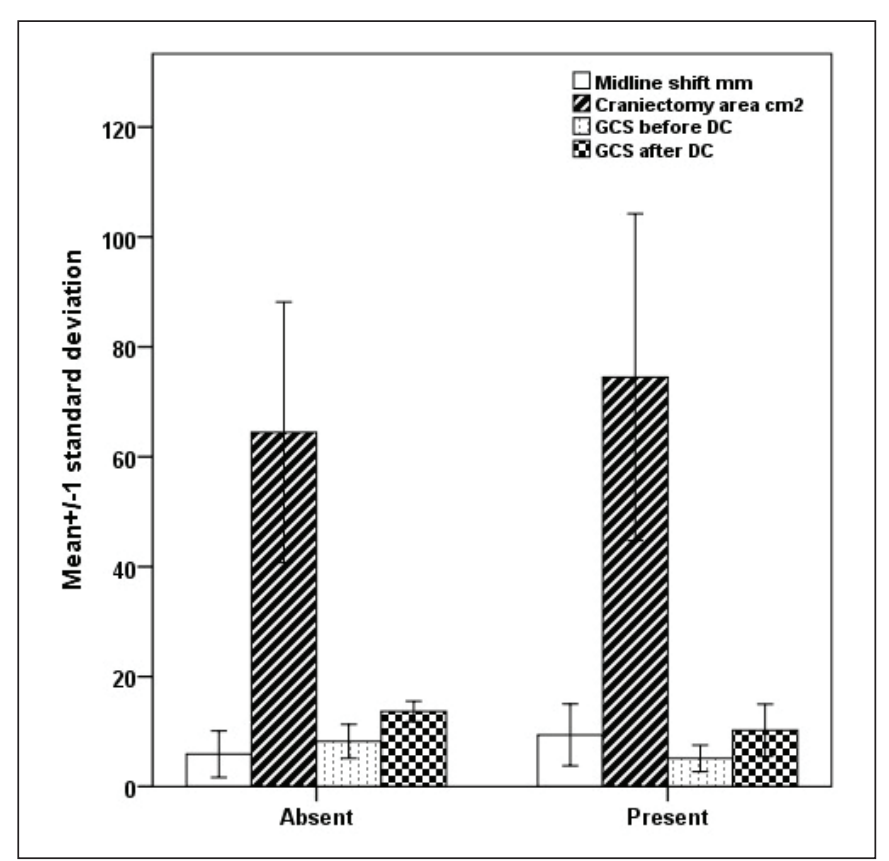

Figure 3: Bar graph with mean +/- standard deviation of variables by ventriculomegaly.

Table III: Distribution of Quantitative Variables in Patients with Shunt Surgery

\begin{tabular}{lccc}
\hline & \multicolumn{2}{c}{ Shunt surgery } & \\
\cline { 2 - 3 } & $\begin{array}{c}\text { Absent } \\
(\mathbf{n}=\mathbf{2 8})\end{array}$ & $\begin{array}{c}\text { Present } \\
(\mathbf{n}=\mathbf{4})\end{array}$ & $\mathbf{p}_{\mathbf{1}}$ \\
\hline Age & $43.43 \pm 19.74$ & $25.75 \pm 11.84$ & 0.094 \\
\hline Midline shift & $6.18 \pm 3.85$ & $11.25 \pm 7.68$ & $\mathbf{0 . 0 3 9}$ \\
\hline Craniectomy area & $59.56 \pm 22.69$ & $76.35 \pm 22.94$ & 0.177 \\
\hline GCS before DC & $7.79 \pm 3.12$ & $4.25 \pm 1.89$ & $\mathbf{0 . 0 3 6}$ \\
\hline GCS after DC & $13.14 \pm 2.43$ & $9.5 \pm 6.56$ & $\mathbf{0 . 0 3 6}$ \\
\hline $\mathbf{p}_{2}$ & $<\mathbf{0 . 0 0 1}$ & $\mathbf{0 . 0 0 3}$ & \\
\hline
\end{tabular}

p1: Comparison between groups, p2: Comparison with in a group. Variance analysis was used in repeated measures.

Table IV: Occurence of Ventriculomegaly Based on Cranioplasty Time

\begin{tabular}{lccccc}
\hline & \multicolumn{4}{c}{ Ventriculomegaly } & p \\
\cline { 2 - 4 } & \multicolumn{2}{c}{ Absent } & Present & \\
\hline $\begin{array}{l}\text { Cranioplasty } \\
\text { heterogenous graft }\end{array}$ & 5 & $8.4 \pm 4.1$ & 1 & $20 \pm$. & - \\
\hline $\begin{array}{l}\text { Cranioplasty } \\
\text { autogenous graft }\end{array}$ & 15 & $6.73 \pm 3.2$ & 8 & $9.5 \pm 3.02$ & 0.057 \\
\hline Cranioplasty total & 20 & $7.15 \pm 3.41$ & 9 & $10.67 \pm 4.5$ & $\mathbf{0 . 0 2 8}$ \\
\hline
\end{tabular}

Independent Samples t Test was used to compare the continuous data between groups.
There was no significant association between age and ventriculomegaly or between epidural hygroma and variables like GCS, midline shift and craniectomy area (Table V).

\section{DISCUSSION}

DC has been described as an emergent surgical procedure that provides extra space for oedematous brain tissue by removing a portion of the cranium. Previous reports in the literature show that DC decreases mortality and improves outcome $(17,26)$. In this study, there was statistically significant improvement in the GCS of all patients following DC surgery. Therefore, the results of this study support the findings in the literature that DC improves outcome.

Although DC has been described as a life-saving intervention in many studies, it is also associated with several complications, of which hydrocephalus is the most common. In addition, some studies in the literature with limited number of patients also cite varying incidence of ventriculomegaly ranging from $0 \%$ to $80 \%(9,21)$. In the present study, the incidence of ventriculomegaly and shunt-dependent hydrocephalus was $28.1 \%$ and $12.5 \%$, respectively. This result is consistent with other studies in the literature (25). Various mechanisms have been proposed regarding the development of hydrocephalus after DC. These include ICP dynamics, mechanical blockage by inflammation, arachnoid granulation or postsurgical debris and neuronal loss $(3,7,14,20)$. In our opinion, altered ICP dynamics affecting the flow, production and absorption of CSF is the most important. This mechanism, combined with the factors associated with cerebral injury, increases the risk of hydrocephalus development. Several studies present clinical factors that may be associated with the development of hydrocephalus after DC surgery. Haemorrhage (24), injury severity (10), GCS (25), duraplasty, bilateral craniectomy (3), multiple surgeries, age (12), delayed craniectomy (26), and distance of craniectomy from the midline (4), are the factors that most commonly affect the development of hydrocephalus after DC. Studies in the literature report varying results with some of the aforementioned factors found to be significant

Table V: Distribution of Quantitative Variables in Patients with Epidural Hygroma

\begin{tabular}{lccc}
\hline & \multicolumn{2}{c}{ Epidural hygroma } & \\
\cline { 2 - 3 } & $\begin{array}{c}\text { Absent } \\
(\mathbf{n}=\mathbf{1 9})\end{array}$ & $\begin{array}{c}\text { Present } \\
(\mathbf{n}=\mathbf{1 3})\end{array}$ & $\mathbf{p}_{\mathbf{1}}$ \\
\hline Age & $42.74 \pm 21.42$ & $39 \pm 17.49$ & 0.606 \\
\hline Midline shift & $6.76 \pm 3.66$ & $6.88 \pm 5.96$ & 0.943 \\
\hline Craniectomy area & $55.90 \pm 18.60$ & $70.07 \pm 26.92$ & 0.088 \\
\hline GCS before DC & $7.89 \pm 3.09$ & $6.54 \pm 3.31$ & 0.245 \\
\hline GCS after DC & $13.11 \pm 2.54$ & $12.08 \pm 4.19$ & 0.394 \\
\hline $\mathrm{p}_{2}$ & $<\mathbf{0 . 0 0 1}$ & $<\mathbf{0 . 0 0 1}$ & \\
\hline
\end{tabular}

p1: Comparison between groups, p2: Comparison within a group. Variance analysis was used in repeated measures. 
in some studies and insignificant in others. This variability may be due to the relatively small number of patients enrolled in these studies. In our study, GCS, midline shift and craniectomy area were found to be the predisposing factors for the development of hydrocephalus after DC. It was found that lower GCS, higher midline shift and higher craniectomy area were significantly associated with development of hydrocephalus after DC. Our results are consistent with some studies in the literature $(3,10,25)$, but differ from others $(5,23)$.

An important finding of this study is that larger craniectomy area is correlated with hydrocephalus. GCS and midline shift are indicators of cerebral injury severity. Cerebral injury severity may increase the risk of hydrocephalus formation independent of DC surgery and vice versa.

Our results are also consistent with studies reporting that early cranioplasty reduces the development of DC-related hydrocephalus (26). In our study, late cranioplasty was associated with increased risk of hydrocephalus development. One proposed theory for this observation is that early cranioplasty may prevent the development of hydrocephalus by maintaining ICP $(14,20)$.

Some cranioplasty-related complications are also reported in the literature. Infection, hematoma and bone flap problems are among the most commonly reported complications. Previously, epidural hygroma was presented as a rare complication after cranioplasty (18). However, recent studies have found epidural hygroma to be one of the most common complications with reported incidences of over 50\% $(15,16)$. Consistent with these recent studies, our study found the incidence of epidural hygroma to be $44.8 \%$. Spontaneous regression was detected in $76.9 \%$ of our patients with epidural hygroma. In $23.1 \%$ of the remaining patients, surgical intervention was required for hygroma evacuation due to progressive increase in its size. This data is also consistent with the literature (15). Although the mechanism underlying development of epidural hygroma is not clear, theories including CSF leakage, dural calcification and presence of air bubbles have been proposed $(1,8,15,16)$. We hypothesise that altered ICP following cranioplasty may potentially contribute to hygroma formation due to the inability of the cerebral parenchyma to rapidly adapt to the sudden change in pressure. There is no definitive information in the literature about prevention of hygroma after cranioplasty. Accordingly, our study did not find an association between epidural hygroma and any of the variables measured. In our opinion, it may be useful to place a drain in the epidural space during each cranioplasty and leave it in place for an extended period of time. Although spontaneous regression of hygroma is possible, close attention should be paid to the possibility of hygroma progression. There is no defined treatment modality in the literature for progression of hygroma (15). Evacuation and epidural drain placement were the preferred treatment modalities in our clinic. Residual fluid or recurrence of hygroma was not detected in these patients during follow-up.

Another important subject that warrants discussion is the treatment of hydrocephalus in patients with DC. According to the literature and our study results, early cranioplasty may prevent DC-related hydrocephalus (26). However, there is no consensus on the treatment of hydrocephalus after DC. Shunt surgery may be performed with or without simultaneous cranioplasty $(18,19)$. In our study, shunt surgery alone was performed in two patients. This caused excessive inward collapse in the craniectomy area and cerebral shift in the direction opposite to the craniectomy area. Therefore, we first closed the shunts of these patients and then performed cranioplasty after the shifts and collapse had normalised. The shunts were then reopened during the same surgery as the cranioplasty. To avoid this complication, shunt surgery followed by cranioplasty was performed simultaneously in the subsequent patients. No complication was encountered in the follow-up of these patients. One previously published study reported fewer complications when cranioplasty and ventriculostomy were performed simultaneously, followed by placement of a ventriculoperitoneal shunt in a subsequent surgery (19). Although this method was found to be relatively safe, it requires three different surgical procedures to be performed in two separate surgeries. In our opinion, our method of performing cranioplasty and shunt surgery simultaneously is more effective because it requires only two different procedures to be performed in a single surgery.

Finally, we have to emphasise the limitations of this study including small participant number and retrospective study design.

\section{REFERENCES}

1. Chang V, Hartzfeld P, Langlois M, Mahmood A, Seyfried D: Outcomes of cranial repair after craniectomy. J Neurosurg 112:1120-1124, 2010

2. Chen CC, Cho DY, Tsai SC: Outcome of and prognostic factors for decompressive hemicraniectomy in malignant middle cerebral artery infarction. J Clin Neurosci 14:317-321, 2007

3. Choi I, Park HK, Chang JC, Cho SJ, Choi SK, Byun BJ: Clinical factors for the development of posttraumatic hydrocephalus after decompressive craniectomy. J Korean Neurosurg Soc 43:227-231, 2008

4. De Bonis P, Pompucci A, Mangiola A, Rigante L, Anile C: Posttraumatic hydrocephalus after decompressive craniectomy: An underestimated risk factor. J Neurotrauma 27:1965-1970, 2010

5. De Bonis P, Sturiale CL, Anile C, Gaudino S, Mangiola A, Martucci M, Colosimo C, Rigante L, Pompucci A: Decompressive craniectomy, interhemispheric hygroma and hydrocephalus: A timeline of events? Clin Neurol Neurosurg 115:1308-1312, 2013

6. Erban P, Woertgen C, Luerding R, Bogdahn U, Schlachetzki F, Horn M: Long-term outcome after hemicraniectomy for space occupying right hemispheric MCA infarction. Clin Neurol Neurosurg 108:384-387, 2006

7. Foroglou G, Zander E: Post-traumatic hydrocephalus and measurement of CSF pressure. Acta Radiol Diagn (Stockh) 13:524-530, 1972 
8. Gooch MR, Gin GE, Kenning TJ, German JW: Complications of cranioplasty following decompressive craniectomy: Analysis of 62 cases. Neurosurg Focus 26:E9, 2009

9. Honeybul S: Complications of decompressive craniectomy for head injury. J Clin Neurosci 17:430-435, 2010

10. Honeybul S, Ho KM: Incidence and risk factors for posttraumatic hydrocephalus following decompressive craniectomy for intractable intracranial hypertension and evacuation of mass lesions. J Neurotrauma 29:1872-1878, 2012

11. Jaeger $M$, Soehle $M$, Meixensberger J: Effects of decompressive craniectomy on brain tissue oxygen in patients with intracranial hypertension. J Neurol Neurosurg Psychiatry 74:513-515, 2003

12. Jiao QF, Liu Z, Li S, Zhou LX, Li SZ, Tian W, You C: Influencing factors for posttraumatic hydrocephalus in patients suffering from severe traumatic brain injuries. Chin J Traumatol 10:159162,2007

13. Jourdan C, Convert J, Mottolese C, Bachour E, Gharbi S, Artru F: Evaluation of the clinical benefit of decompression hemicraniectomy in intracranial hypertension not controlled by medical treatment. Neurochirurgie 39:304-310, 1993

14. Jüttler E, Schwab $S$, Schmiedek $P$, Unterberg A, Hennerici M, Woitzik J, Witte S, Jenetzky E, Hacke W: Decompressive surgery for the treatment of malignant infarction of the middle cerebral artery (DESTINY): A randomized, controlled trial. Stroke 38:2518-2525, 2007

15. Kim SP, Kang DS, Cheong JH, Kim JH, Song KY, Kong MH: Clinical analysis of epidural fluid collection as a complication after cranioplasty. J Korean Neurosurg Soc 56:410-418, 2014

16. Lee JW, Kim JH, Kang HI, Moon BG, Lee SJ, Kim JS: Epidural fluid collection after cranioplasty: Fate and predictive factors. J Korean Neurosurg Soc 50:231-234, 2011

17. Lee MH, Yang JT, Weng HH, Cheng YK, Lin MH, Su CH, Chang CM, Wang TC: Hydrocephalus following decompressive craniectomy for malignant middle cerebral artery infarction. Clin Neurol Neurosurg 114:555-559, 2012
18. Oh $\mathrm{CH}$, Park CO, Hyun DK, Park HC, Yoon SH: Comparative study of outcomes between shunting after cranioplasty and in cranioplasty after shunting in large concave flaccid cranial defect with hydrocephalus. J Korean Neurosurg Soc 44:211216, 2008

19. Pachatouridis D, Alexiou GA, Zigouris A, Michos E, Drosos D, Fotakopoulos G, Voulgaris S: Management of hydrocephalus after decompressive craniectomy. Turk Neurosurg 24:855858, 2014

20. Portnoy HD, Chopp M, Branch C, Shannon MB: Cerebrospinal fluid pulse waveform as an indicator of cerebral autoregulation. J Neurosurg 56:666-678, 1982

21. Rahme R, Weil AG, Sabbagh M, Moumdjian R, Bouthillier A, Bojanowski MW: Decompressive craniectomy is not an independent risk factor for communicating hydrocephalus in patients with increased intracranial pressure. Neurosurgery 67:675-678, 2010

22. Reithmeier T, Lohr M, Pakos P, Ketter G, Ernestus Rl: Relevance of ICP and ptiO(2) for indication and timing of decompressive craniectomy in patients with malignant brain edema. Acta Neurochir (Wien) 147:947-952,2005

23. Takeuchi S, Takasato Y, Masaoka H, Hayakawa T, Yatsushige $\mathrm{H}$, Shigeta K, Nagatani K, Otani N, Wada K, Nawashiro H, Shima K: Hydrocephalus after decompressive craniectomy for hemispheric cerebral infarction. J Clin Neurosci 20:377382,2013

24. Tian HL, Xu T, Hu J, Cui YH, Chen H, Zhou LF: Risk factors related to hydrocephalus after traumatic subarachnoid hemorrhage. Surg Neurol 69:241-246, 2008

25. Wang Q, Ma J, Zhou Z, Yang M, You C: Hydrocephalus after decompressive craniectomy for malignant hemispheric cerebral infarction. Int J Neurosci 126:707-712, 2015

26. Waziri A, Fusco D, Mayer SA, McKhann GM 2nd, Connolly ES Jr: Postoperative hydrocephalus in patients undergoing decompressive hemicraniectomy for ischemic or hemorrhagic stroke. Neurosurgery 61:489-493, 2007 